\title{
PENJAMINAN MUTU INTERNAL PERGURUAN TINGGI
}

\author{
Halimatus Sakdiah \\ Dosen Tetap Fakultas Dakwah IAIN Antasari Banjarmasin
}

\begin{abstract}
There are many higher education executives in Indonesia that still carry out fewer learning activities under the quality standards, so ultimately the credibility of higher education is still not satisfying the stakeholders. A college should be able to make internal quality standards beyond the minimum quality standards made by the National Education Standards Agency (BSNP). Currently, quality assurance in the form of systems development and the establishment of the agency has not been done much in the college. The role of internal quality assurance for higher education is also still inadequate to boost quality improvement. This is where the need for internal quality assurance agency in college that aims to repair and improve the quality of higher education on an ongoing basis.
\end{abstract}

Keywords : Internal Quality Assurance and Higher Education.

\section{Pendahuluan}

Perguruan Tinggi sebagai lembaga pendidikan tinggi formal, sampai saat ini masih dianggap sebagai sumber ilmu pengetahuan, etika dan nilai kebijakan. Anggapan tersebut telah melekat pada setiap perguruan tinggi, sehingga mutu lulusannya diharapkan memiliki kriteria "smart" dan "good", Namun di sisi lain, kondisi perguruan tinggi di Indonesia masih banyak yang belum melaksanakan kegiatan pembelajaran sesuai dengan standar mutu, hingga pada akhirnya kredibilitas perguruan tinggi masih belum memuaskan para stakebolders. Bila penyelenggara pendidikan tinggi di Indonesia tidak segera melakukan upaya-upaya nyata meningkatkan kualitas input, proses, output maupun outcome-nya, maka eksistensi perguruan tinggi tersebut akan semakin surut.

Fenomena yang terjadi sekarang ini masyarakat Indonesia banyak mencari pendidikan tinggi yang berkualitas ke luar negeri, misalnya ke negara tetangga Malaysia. Meyikapi hal tersebut pemerintah Indonesia pada tahun 2003 melalui Direktorat Akademik mulai menggagas kegiatan 


\section{Halimatus Sakdiah}

Penjaminan Mutu (Quality Assurance) di perguruan tinggi. Merujuk pada Undang-Undang Nomor 20 tahun 2003 tentang Sistem Pendidikan Nasional, Higher Education Long Term Strategy (HELTS) 2003-1010, dan Peraturan Pemerintah No 19 tahun 2005 tentang Standar Nasional Pendidikan pelaksanaan penjaminan mutu di perguruan tinggi merupakan kegiatan yang wajib dilakukan. Sistem penjaminan mutu perguruan tinggi (PT) dilakukan atas dasar Penjaminan Mutu Internal (PMI), Penjaminan Mutu Eksternal (PME), dan Evaluasi Program Studi Berbasis Evaluasi Diri (EPSBED) yang dikaitkan dengan perijinan penyelenggaraan program studi.

Pada tahun 2005 terbit Peraturan Pemerintah Nomor 19 Tahun 2005 tentang Standar Nasional Pendidikan (SNP), yang menyatakan bahwa SNP bertujuan untuk menjamin mutu pendidikan nasonal. Dengan demikian implementasi penjaminan mutu selain wajib memenuhi SNP juga memberikan kebebasan pada setiap perguruan tinggi untuk mengembangkan penjaminan mutu sesuai sejarah, visi, misi, budaya, ukuran, dan berbagai kekhasan dari perguruan tinggi tersebut. Dengan pola implementasi seperti ini, dalam kurun waktu tujuh tahun tentu telah berlangung beragam implementasi penjaminan mutu, baik pada aras perguruan tinggi maupun pada aras Nasional.

Namun persoalan yang dihadapi penjaminan mutu bukan semata masalah akreditasi program studi, tetapi juga masalah akreditasi institusi akuntabilitas public, penjaminan mutu internal (evaluasi diri) yang tidak berjalan sesuai prosedur semestinya, tidak adanya standar mutu internal perguruan tinggi, tidak adanya organisasi penjamin mutu internal dan sebagainya. Persoalan ini bukan semata masalah kinerja organisasi, tetapi juga menyangkut masalah kebijakan makro, dan implementasinya di lapangan. Hal ini tentunya tidak hanya memperlemah penjaminan mutu, tetapi juga memperlemah perbaikan mutu perguruan tinggi secara keseluruhan.

Berdasarkan hasil evaluasi Direktorat Jenderal Pendidikan Tinggi Kementerian Pendidikan Nasional (2008) tentang implementasi penjaminan mutu internal di perguruan tinggi dinyatakan bahwa:

- Sebagian besar perguruan tinggi belum memahami secara utuh fungsi dan peran penjaminan mutu bagi pengembangan dan keberlanjutannya. 
- Sebagian besar perguruan tinggi belum memahami tentang Sistem Penjaminan Mutu Perguruan Tinggi (SPM-PT) yang digagas oleh Ditjen.Dikti.

- Sebagian besar perguruan tinggi masih memokuskan pada penjaminan mutu internal bidang akademil (hanya focus pada aspek pembelajaran).

- Sebagian besar perguruan tinggi masih dalam taraf pengadaan dokumen, baik dokumen kebijakan, manual penerapan kebijakan standar mutu.

- Sebagian kecil perguruan tinggi telah mengimplementasikan penjaminan mutu internal secara penuh (memiliki kelengkapan dokumen kebijakan, manual penerapan kebijakan standar mutu, dan mengimplementasi-kannya).

Merujuk hasil evaluasi dari Direktorat Jenderal Pendidikan Tinggi tahun 2008 di atas maka perguruan tinggi perlu secara kritis melihat kembali peran dan kinerjanya selama ini. Kualitas menjadi kepedulian dan perlu mendapat perhatian serius baik lembaga, pemerintah maupun stakeholders yang terkait dengan pendidikan. Peningkatan mutu di setiap lembaga pendidikan bukan sekedar verbalisme, namun harus diwujudkan melalui suatu proses yang disengaja, direncanakan, diorganisir dan dikendalikan semua pihak melalui team work spirit.

Sebagai salah satu sub sistem dari Sistem Penjaminan Mutu Perguruan Tinggi (SPM-PT), penjaminan mutu internal yang telah diimplementasikan oleh perguruan tinggi di Indonesia, perlu dievaluasi keberhasilannya untuk perbaikan dan peningkatan mutu perguruan tinggi secara berkelanjutan. Berdasarkan uraian tersebut di atas, pembahasan dalam makalah ini akan difokuskan pada pentingnya penjaminan mutu internal perguruan tinggi.

\section{Konsep Penjaminan Mutu Internal}

Mutu pendidikan adalah nilai, manfaat, kesesuaian dengan suatu spesifikasi tertentu atas input, proses dan output pendidikan yang dirasakan oleh konsumen pemakai jasa pendidikan. Jadi, dalam defnisi mutu pendidikan ini tercakup didalamnya adalah mutu input pendidilkan, pross pendidikan maupun output pendidikan. Mutu input terkait dengan 


\section{Halimatus Sakdiah}

kualitas masukan pendidikan seperti animo masyarakat untuk mendaftar sebagai calon siswa baru dan tingkat kemampuan siswa baru yang diterima oleh lembaga pendidikan tersebut. Selain itu, instrumental input seperti kurkulum, pendidik dan tenaga kependidikan, sarana dan prasarana serta sumber daya yang dimiliki lembaga pendidikan bersangkutan.

Penjaminan mutu pendidikan adalah serentetan proses dan sistem yang saling berkaitan untuk mengumpulkan, menganalisis, dan melaporkan data tentang kinerja dan mutu pendidik dan tenaga kependidikank lembaga pendidikan. Proses penjaminan mutu mengidentifikasi aspek pencapaian dan prioritas peningkatan, penyediaan data sebagai dasar perencanaan dan pengambilan keputusan serta membantu membangun budaya peningkatan mutu berkelanjutan. Penjaminan mutu akan berkontribusi terhadap peningkatan mutu pendidikan.

Don Adam et al. (1991 dalam Nurdin, 2009) kualitas pendidikan tinggi didefinisikan sebagai "outputs, input or process characteristic of formal or non formal education. Typical output measures include student achievment (or such proxies as completion rates and various form of certification) literacy and pratical skills". Penjaminan mutu internal adalah penjaminan mutu yang dilakukan oleh institusi perguruan tinggi dengan cara yang ditetapkan perguruan tinggi pelaksana. Parameter dan metoda mengukur hasil ditetapkan oleh perguruan tinggi sesuai visi dan misinya. Dengan menjalankan penjaminan mutu internal, maka institusi pendidikan tinggi sebaiknya melakukan evaluasi internal. Evaluasi diri. dimaksudkan untuk mengupayakan peningkatan kualitas berkelanjutan (Direktorat Jenderal Pendidikan Tinggi, 2006). Mutu institusi perguruan tinggi merupakan totalitas keadaan dan karakteristik masukan, proses dan produk atau layanan institusi perguruan tinggi yang diukur dari sejumlah standar sebagai tolok ukur penilaian untuk menentukan dan mencerminkan mutu institusi perguruan tinggi.

\section{Penjaminan Mutu Internal di Perguruan Tinggi}

Tuntutan masyarakat terhadap mutu perguruan tinggi sebagai akibat globalisasi merupakan masalah konkrit, yang pemecahannya tidak bisa ditunda-tunda. Ini berarti, proses pembelajaran di perguruan tinggi harus bermutu dan memenuhi standar mutu yang ditetapkan. Eksistensi dan tantangan sebuah perguruan tinggi tergantung pada penilaian stakebolders. 
Karena itu, perguruan tinggi perlu menjalankan proses penjaminan mutu terhadap pendidikan yang diselenggarakannya.

Komponen penentu mutu proses dan lulusan perguruan tinggi terdiri dari banyak komponen, di antaranya mutu program akademik, sumberdaya manusia, sarana prasarana, dan suasana akademik. Berbagai komponen mutu tersebut perlu ditingkatkan dalam rangka memenuhi standar nasional pendidikan. Pemerintah dengan Peraturan Pemerintah Nomor 19 Tahun 2005 (Standar Nasional Pendidikan) pasal 2, menyatakan bahwa untuk penyelenggaraan setiap satuan pendidikan harus mengacu delapan standar mutu pendidikan, yakni: standar isi, proses, kompetensi lulusan, pendidik dan tenaga kependidikan, sarana dan prasarana, standar pengelolaan, pembiayaan, dan standar penilaian pendidikan. Hal ini telah ditegaskan dalam Undang-undang Republik Indonesia Nomor 20 Tahun 2003 tentang Sistem Pendidikan Nasional pasal 35 ayat 3, bahwa untuk mencapai mutu standar pendidikan itu tidak hanya ditentukan oleh unsur tenaga kependidikan yakni dosen, tetapi juga bagaimana pengelolaan perguruan tinggi itu atas standar isi, proses, kompetensi lulusan, sarana dan prasarana, pengelolaan, pembiayaan, dan penilaian pendidikan yang dapat dilaksanakan oleh suatu badan standarisasi, penjaminan dan pengendalian mutu pendidikan (Sumardjoko, 2010:.294-310).

Saat ini badan penjaminan mutu internal harus berpartisipasi aktif membina dan melakukan perbaikan mutu perguruan tinggi. Peduli mutu saja tidak cukup, perguruan tinggi memerlukan bantuan dan pelayanan. Permbinaan dan perbaikan mutu dapat dilakukan dengan pihak eksekutif, khususnya wakil rector bidang akademik karena hakikatnya merekalah yang bertanggung jawab langsung terhadap mutu perguruan tinggi. Badan penjamin internal bertindak sebagai "guru mutu" yang melayani dan mendorong institusi dan program studi melakukan evaluasi diri dan akreditasi kepada badan penjamin mutu eksternal.

Untuk melaksanakan SPM-PT' perlu bertahap sesuai dengan kesiapan perguruan tinggi, namun sebaiknya disusun kerangka waktu yang jelas untuk pelaksanaannya. Pelaksanaan SPM-PT pada umumnya dimulai pada kegiatan pendidikan terlebih dahulu, baru kemudian dikembangkan di bidang penelitian kemudian pengabdian kepada masyarakat. Dengan demikiandapatmencakup kegiatanakademik. Setelahmampumelaksanakan 


\section{Halimatus Sakdiah}

SPM-PT di bidang akademik, kemudian dapat dikembangkan ke bidang yang lebih luas, misalnya keuangan, sumberdaya manusia dan seterusnya. Tujuan akhir adalah SPM-PT untuk seluruh bidang yang terkait dengan pengelolaan perguruan tinggi secara keseluruhan sehingga sangat erat dengan kesehatan organisasi untuk menjamin mutu aspek akademik maupun non akademik perguruan tinggi di Indonesia.

\section{Sistem Penjaminan Mutu Internal}

Sistem penjaminan mutu perguruan tinggi dapat dibedakan menjadi dua bagian, yaitu; penjaminan mutu internal dan penjaminan mutu eksternal. Penjaminan mutu internal (internal quality assurance) bentukannya berupa evaluasi diri yang dilakukan oleh program studi atau institusi perguruan tinggi. Tujuannya untuk memperbaiki kinerja dan memberi penjaminan mutu internal, khususnya kepada para stakeholder internal perguruan tinggi, seperti para pimpinan, dosen, peneliti, karyawan dan mahasiswa.

Pengembangan system penjaminan mutu internal pada perguruan tinggi ada berbagai macam bentuk, misalnya; Universitas Indonesia (UI) membentuk organisasi berjenjang, mandiri dan nonstructural, yaitu BPMA (Badan Penjaminan Mutu Akademik), Institut Teknologi Bandung (ITB) mendirikan Satuan Penjaminan Mutu. Organisasi ini bertanggung jawab terhadap rector. Dalam struktur organisasi, SPM-ITB adalah organisasi mandiri yang berada pada sayap kiri-kanan dengan Satuan Pengawas Internal (SPI) setara dengan Wakil Rektor Senior. SPM-ITB adalah organisasi tingkat pusat yang memiliki susunan berjenjang. Sedang di tingkat fakultas dan program studi disebut Gugus Kendali Mutu (GKM), yang berfungsi untuk mengembangkna dan menjabarkan system penjaminan mutu, serta melaksanakannya pada seluruh fakultas dan unit kerja yang ada. Hal ini berbeda dengan SPM Universitas Pendidikan Indonesia (UPI) yang susunan kepengurusannya terdiri atas ketua, sekretaris, dan tim SPM, organisasinya hanya sekedar bagian dari Unit Penunjang Kegiatan, bukan suatu organisasi mandiri dan berjenjang. SPM UPI hanya ada dalam administrasi Rektorat dan belum sampai ke tingkat fakultas dan program studi (Ghafur, 2010).

Seperti halnya UPI, Universitas Gajah Mada juga tidak membentuk organisasi khusus secara berjenjang. Penjaminan mutu menjadi tugas dan 
fungsi dari Direktorat Akademik dan Lembaga Penelitian dan Pengabdian Kepada Masyarakat (LPPM), yang bertugas mengembangkan system penjaminan mutu, evaluasi diri, dan pembuatan standar mutu UGM. Begitu pula dengan Institut Pertanian Bogor (IPB) juga tidak membentuk organisasi khusus yang mandiri dan berjenjang. Penjaminan mutu di IPB adalah menjadi tugas dan fungsi DirektoratnAdministrasi dan Jaminan Mutu Pendidikan di bawah koordinasi Wakil Rektor I (Bidang akademik). Baik UI, UPI, IPB dan UGM adalah contoh kasus yang kurang tepat, karena penjaminan mutu hanya dikaitkan dengan kegiatan akademik semata. Dalam perspektif penjaminan mutu terpadu (total quality assurance system) yang harus mendapat penjaminan mutu bukan hanya kegiatan akademik saja, tetapi seluruh kegiatan baik akademik maupun non akademik (Hanief Saha Ghafur, 2010).

Dengan demikian system pelaksaan penjaminan mutu internal selama ini dapat dibedakan menjadi tiga kategori, yaitu; 1) perguruan tinggi yang mengembangkan system penjamin mutu secara khusus, tanpa mendirikan organisasi khusus. Tugas dan fungi untuk pengembangan mutu dilakukan oleh senat akademik bekerjasama dengan seluruh jajaran pimpinan, 2) perguruan tinggi yang mendirikan organisasi untuk mengembangkan system penjaminan mutu secara internal. Ada dua kategori organisasi, yaitu a) organisasi khusus yang mandiri, baik bejrejang mulai dari tingkat pusat, fakultas dan program studi, maupun yang tidak berjenjang, b) organisasi yang menyatu dengan struktur organisasi dan system administrasinya; 3) perguruan tinggi yang tidak mengembangkan sistem penjaminan mutu khusus dan tidak mendirikan organisasi khusus. Kategori ketiga inilah yang terbanyak pada PTS dan PTN non BHMN.

Demikian juga tentang syarat Sistem Penjaminan Mutu Organisasi/ institusi harus menetapkan, mendokumentasikan, mengimplementasikan, memelihara dan meningkatkan secara berkelanjutan (continual improvement) SMM sesuai dengan persyaratan,pedoman dan standar yang ditentukan Prinsip Sistem Penjaminan Mutu. Tuliskan apa yang dilakukan/ dikerjakan dan lakukan/kerjakan apa yang ditulis. Kebanyakan perguruan tinggi melakukan apa yang seharusnya dikerjakan namun sangat kurang dalam domentasi, dan ada juga dokumentasinya lengkap namun tidak sesuai dengan implementasinya di lapangan. Hanya sebagian kecil perguruan 
tinggi yang memenuhi syarat sistem penjaminan mutu.

\section{Standar Penjaminan Mutu Internal}

Standar SPMI-PT adalah dokumen tertulis berisi berbagai kriteria, ukuran, patokan atau spesifikasi dari seluruh kegiatan penyelenggaraan pendidikan tinggi suatu PT untuk mewujudkan visi dan misinya, agar dapat dinilai bermutu sesuai dengan ketentuan perundang-undangan sehingga memuaskan para pemangku kepentingan internal dan eksternal PT. Perguruan tinggi dinyatakan bermutu, apabila mampu memenuhi Standar Nasional Pendidikan (SNP) (aspek imperatif), perguruan tinggi mampu menetapkan dan mewujudkan visinya melalui pelaksanaan misinya (aspek deduktif), perguruan tinggi mampu memenuhi kebutuhan stakebolders (aspek induktif). Dokumen tertulis Standar SPMI-PT (Standar Mutu) berfungsi antara lain:

1) Alat untuk mewujudkan visi, misi, dan tujuan PT.

2) Indikator untuk menunjukkan tingkat (level) mutu P'T.

3) Tolok ukur yang harus dicapai semua pihak di dalam PT sehingga menjadi faktor pendorong untuk bekerja dengan, atau bahkan melebihi, standar.

4) Bukti otentik kepatuhan PT terhadap peraturan dan publik bahwa PT memiliki dan memberikan layanan pendidikan dengan menggunakan standar.

Penetapan standar dan mekanisme penjaminan mutu adalah otoritas perguruan tinggi, yang penting adalah upaya benchmarking mutu pendidikan tinggi berkelanjutan. Selama ini kebanyakan perguruan tinggi di Indonesia telah menetapkan standar mutu internal untuk menjamin mutu perguruan tinggi, dalam bentuk document tertulis hanya pada tingkat institute, sementara dalam tingkat fakultas maupun program studi masih sedikit, mengingat tidak semua perguruan tinggi memiliki badan penjaminan mutu tingkat fakultas dan program studi. 


\section{Langkah-Langkah menuju Sistem Jaminan Mutu yang Efektif}

Dalam rangka mewujudkan akuntabilitas, perguruan tinggi harus aktif membangun sistem penjaminan mutu internal. Untuk membuktikan bahwa sistem penjaminan mutu internal telah dilaksanakan dengan baik dan benar, perguruan tinggi harus diakreditasi oleh lembaga penjaminan mutu eksternal. Dengan sistem penjaminan mutu yang baik dan benar, perguruan tinggi akan mampu meningkatkan mutu, menegakkan otonomi, dan mengembangkan diri sebagai institusi akademik dan kekuatan moral secara berkelanjutan (BAN PT, 2007).

Menurut Ghafur (2010) agar system penjaminan mutu dapat memperbaiki penjaminan mutu maka diperlukan system penjaminan mutu yang terpadu antara system penjaminan mutu internal dan eksternal menjadi satu daur dengan system perbaikan mutu berkelanjutan. Hubungan dua sistem dalam satu daur perbaikan mutu berkelanjutan dapat digambarkan dalam suatu matriks sebagai berikut:

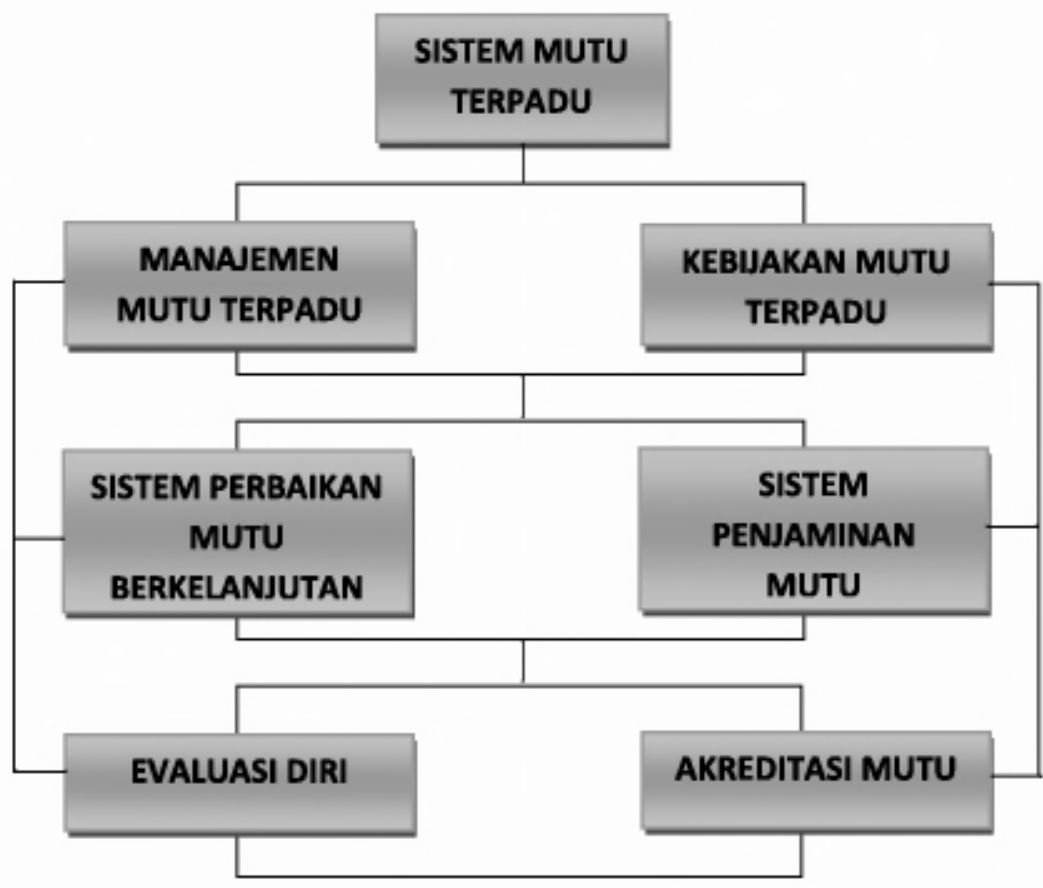

Gambar:

Sistem Penjaminan Mutu dalam Satu Daur Perbaikan Mutu Berkelanjutan 


\section{Halimatus Sakdiah}

Pelaksanaan sistem penjaminan mutu dalam satu daur perbaikan mutu berkelanjutan pada perguruan tinggi dapat dilakukan melalui empat tahap kegiatan, yaitu; 1) memperbaiki perencanaan mutu, 2) mempertegas komitmen kebijakan mutu yang implementatif, 3) melakukan pengorganissian mutu dengan tata kelola yang baik, dan 4) melakukan evaluasi dan pemantauan. Empat tahap kegiatan ini perlu dipertegas dengan komitmen kebijakan Kemendiknas, karena kebijakan ini bukan hanya dibutuhkan untuk perbaikan mutu, tetapi juga dibutuhkan sebagai jaminan kepada masyarakat, khususnya kepada stakeholder.

Untuk menjalankan daur di atas, diperlukan rumusan kebijakan yang jelas dan tegas agar perguruan tinggi segera mendirikan badan dan unit pelaksana penjaminan secara berjenjang, mulai dari pusat administrasi/ institute sampai di tingkat program studi. Penjaminan mutu diperguruan tinggi bisa dilakukan baik secara menyeluruh maupun secara berjenjang. Yang dimaksud dengan menyeluruh berarti seluruh proses yang terkait dalam PT tersebut seperti penerimaan mahasiswa baru, perkuliahan (proses belajar mengajar), hingga proses meluluskan mahasiswa dijaminkan mutunya. Sedangkan yang dimaksud dengan bertahap adalah PT bisa melakukan penjaminan mutu bukan seluruh proses yang dilakukan PT melainkan hanya tridarma (pendidikan, penelitian dan pengabdian masyarakat) atau hanya salah satu darma saja (Eko Prasetyo, 2009).

Agar penjaminan mutu internal pendidikan tinggi dapat dilaksanakan, maka beberapa prasyarat yang harus dipenuhi, yaitu komitmen, perubahan paradigma, dan sikap mental para pelaku proses pendidikan tinggi, serta pengorganisasian penjaminan mutu di perguruan tinggi (Dirjen Dikti 2003). Hal tersebut dapat diuraikan sebagai berikut:

\section{- Komitmen}

Para pelaku proses pendidikan tinggi di suatu perguruan tinggi, baik yang memimpin maupun yang dipimpin, harus memiliki komitmen yang tinggi untuk senantiasa menjamin dan meningkatkan mutu pendidikan tinggi yang diselenggarakannya. Tanpa komitmen ini di semua lini organisasi suatu perguruan tinggi, niscaya penjaminan mutu pendidikan tinggi di perguruan tinggi tersebut akan berjalan tersendat, bahkan mungkin tidak akan berhasil dijalankan. Terdapat aneka cara yang dapat dipilih 
untuk menggalang komitmen dari semua lini di suatu perguruan tinggi, tergantung dari ukuran, struktur, sumber daya, visi dan misi, sejarah, dan kepemimpinan dari/di perguruan tinggi tersebut.

- Perubahan Paradigma

Paradigma baru penjaminan mutu pendidikan tinggi, yaitu perguruan tinggi harus menjaga dan meningkatkan mutu pendidikan tinggi yang diselenggarakannya agar visinya dapat diwujudkan melalui pelaksanaan misi, serta agar stakeholders dapat dipuaskan. Dengan paradigma baru tersebut, tugas pengawasan oleh pemerintah diringankan, akuntabilitas perguruan tinggi meningkat, stakeholders berperan lebih besar dalam menentukan mutu pendidikan tinggi di suatu perguruan tinggi.

- Sikap Mental

Harus diakui bahwa sebagian terbesar perguruan tinggi di Indonesia menyelenggarakan pendidikan tinggi tanpa didahului dengan perencanaan. Dapat dikemukakan fakta bahwa dalam skala makro, Rencana Induk Pengembangan (RIP) suatu perguruan tinggi, sebagian besar disusun untuk memenuhi persyaratan akreditasi, sedangkan dalam skala mikro dapat dikemukakan fakta tentang rendahnya persentase dosen yang membuat rencana pembelajaran berupa Satuan Acara Perkuliahan (SAP), dan masih banyak lagi fakta yang menunjukkan bahwa suatu perguruan tinggi menjalankan pendidikan tinggi tanpa perencanaan.

- Pengorganisasian

Mengenai pengorganisasian serta mekanisme kerja organisasi penjaminan mutu pendidikan tinggi di suatu perguruan tinggi, tidak terdapat pola baku yang harus diikuti oleh semua perguruan tinggi. Pengorganisasian penjaminan mutu pendidikan tinggi di suatu perguruan tinggi sangat tergantung pada ukuran, struktur, sumber daya, visi dan misi, sejarah, dan kepemimpinan dari/di perguruan tinggi tersebut. Sebagai contoh, dapat dikemukakan bahwa suatu perguruan tinggi dapat mengadakan unit penjaminan mutu di dalam struktur organisasinya yang dipimpin oleh seorang wakil rektor, atau suatu unit yang independen terlepas dari struktur organisasi yang dipimpin oleh seorang dosen. 
Selanjutnya beberapa langkah yang dapat dijadikan pedoman bagi para pengelola pendidikan di perguruan tinggi terdiri dari beberapa tahapan. Diantaranya yaitu: 1) penetapan standar, 2) pengujian atau audit mengenai sistem pendidikan yang sedang berlangsung, 3) penyimpulan tentang ada tidaknya kesenjangan antara sistem yang ada dengan standar yang ditetapkan (Nurdin, 2009). Faktor terpenting yang perlu mendapat perhatian dalam pengorganisasian penjaminan mutu pendidikan tinggi, adalah bahwa pengorganisasian tersebut mampu menumbuhkan kesepahaman tentang penjaminan mutu pendidikan tinggi di perguruan tinggi tersebut, yang pada gilirannya akan menumbuhkan sikap suportif dari seluruh komponen di perguruan tinggi itu terhadap upaya penjaminan mutu pendidikan tinggi.

\section{Penutup}

Penjaminan mutu internal adalah penjaminan mutu yang dilakukan oleh institusi perguruan tinggi dengan cara yang ditetapkan perguruan tinggi pelaksana. Parameter dan metoda mengukur hasil ditetapkan oleh perguruan tinggi sesuai visi dan misinya. Tujuan penjaminan mutu internal adalah untuk memperbaiki kinerja dan memberi penjaminan mutu internal, khususnya kepada para stakeholder internal perguruan tinggi, seperti para pimpinan, dosen, peneliti, karyawan dan mahasiswa.

Penjaminan mutu internal (internal quality assurance) bentukannya berupa evaluasi diri yang dilakukan oleh program studi atau institusi perguruan tinggi. Ada berbagai bentuk pengembangan system penjaminan mutu internal pada berbagai perguruan tinggi di Indonesia. Perguruan tinggi dinyatakan bermutu, apabila perguruan tinggi mampu memenuhi Standar Nasional Pendidikan (SNP) (aspek imperatif), perguruan tinggi mampu menetapkan dan mewujudkan, visinya melalui pelaksanaan misinya (aspek deduktif), perguruan tinggi mampu memenuhi kebutuhan stakeholders (aspek induktif). Agar penjaminan mutu internal pendidikan tinggi dapat dilaksanakan, maka beberapa prasyarat yang harus dipenuhi agar dapat mencapai tujuannya, yaitu komitmen, perubahan paradigma, dan sikap mental para pelaku proses pendidikan tinggi, serta pengorganisasian penjaminan mutu di perguruan tinggi 


\section{DAF'TAR PUS'TAKA}

Badan Penjaminan Mutu, 2009. Penjaminan Mutu Perguruan Tinggi, Retrieved on April 11, 2011 from the world wide web: http:/ ipan. staff.uii.ac.id/files/2009/ 02/ konsep-sistem-penjaminan-mutuuii.pdf

Bambang Sumardjoko, 2010. Faktor-Faktor Determinan Peran Dosen

Dalam Penjaminan Mutu Perguruan Tinggi. Jurnal Cakrawala Pendidikan, November 2010, Th. XXIX, No. 3, P.P. 294-310

Ban P'T, 2007. Buku I Naskah Akademik Akreditasi Institusi Perguruan Tinggi, Departemen Pendidikan Nasional, Jakarta

Carolyn Campbell And Christina Rozsnyai, (2002). Quality Assurance And The Development Of Course Programmes, Bucharest, UNESCO.

Direktorat Jenderal Pendidikan Tinggi, 2003, Pedoman Penjaminan Mutu (Quality Assurance), Departemen Pendidikan Nasional

Direktorat Jenderal Pendidikan Tinggi, 2006. Panduan Pelaksanaan Sistem Penjaminan Mutu Perguruan Tinggi (SPM-PT) Bidang Akademik, Departemen Pendidikan Nasional

Direktorat Jenderal Pendidikan Tinggi, 2008. Hasil Implementasi Sistem Pendidikan Mutu Internal Perguruan Tinggi, Departemen Pendidikan Nasional

Eko Prasetyo, 2009. Penjaminan Mutu Perguruan Tinggi, Jurnal Kajian Ilmiah Lembaga Penelitian Ubhara Jaya, Vol.9 No.1 tahun 2009, $750-775$

Hanief Saha Ghafur, 2008. Manajemen Penjaminan Mutu di Perguruan Tinggi: Suatu Analisis Kebijakan, Jakarta: Bumi Aksara

Higher Education Long Term Strategy (Helts) 2003-2010. Departemen Pendidikan Nasional.

Nurdin, 2009. Quality Assurance In Higher Education, Jurnal Administrasi Pendidikan Vol. X No. 2 Okt 2009 94-110

Pedoman Evaluasi Diri Program Studi. 2005. Badan Akreditasi Nasional Perguruan Tinggi (Ban-Pt) - Departemen Pendidikan Nasional.

Pedoman Penjaminan Mutu (Quality Assurance) Pendidikan Tinggi. 2003. 
Direktorat Jenderal Perguruan Tinggi - Departemen Pendidikan Nasional.

Sanjaya Mishra (2007) Quality Assurance in Higher Education: An Introduction, India, National Assessment and Accreditation Council (NAAC)

Sritomo W.Soebroto, t.th. Konsep Dan Pemahaman Tentang Penjaminan Mutu Perguruan Tinggi, Retrieved on April 11, 2011 from the world wide web http://www.its. ac.id/ personal/files/material/1661-m_ sritomo-ie-Penjaminan\%20Mutu\%20 Perguruan\%20Tinggi.pdf

Tim Pengembang SPMI PT, 2010. Sistem Penjaminan Mutu Internal Perguruan Tinggi: Bahan Pelatihan, Direktorat Jenderal Pendidikan Tinggi, Direktorat Akademik

Undang - Undang No. 20 Tahun 2003 Tentang Sistem Pendidikan Nasional Dan Peraturan Pemerintah Republik Indonesia No. 19 Tahun 2005 Tentang Standar Nasional Pendidikan. 